\title{
PERIODYKI NAUKOWE WYDAWANE PRZEZ PRACOWNIKÓW NAUKOWO-DYDAKTYCZNYCH WYDZIALU TEOLOGICZNEGO SEKCJA W TARNOWIE UNIWERSYTETU PAPIESKIEGO JANA PAWLA II W KRAKOWIE
}

Rok 2011 w diecezji tarnowskiej jest Rokiem Jubileuszowym - 225 lat istnienia diecezji tarnowskiej. Jednocześnie w diecezji tarnowskiej od 190 lat istnieje wyższa uczelnia teologiczna - najpierw Wyższe Seminarium Duchowne w Tarnowie, następnie Instytut Teologiczny w Tarnowie, a obecnie Wydział Teologiczny Sekcja w Tarnowie Uniwersytetu Papieskiego Jana Pawła II w Krakowie. Zazwyczaj każdy ośrodek naukowy systematycznie wydaje periodyk naukowy, w którym zawarte 
są poszukiwania naukowe pracowników naukowych danego ośrodka. Również i Wydział Teologiczny Sekcja w Tarnowie, Uniwersytetu Papieskiego Jana Pawła II w Krakowie, który uczestniczy w tradycji naukowej Wyższego Seminarium Duchownego w Tarnowie oraz Instytutu Teologicznego w Tarnowie wydaje periodyki. Należy wskazać, iż pracownicy naukowo-dydaktyczni WTST przygotowują i wydają następujące periodyki naukowe: „Tarnowskie Studia Teologiczne”, “The Person and the Challenges: The Journal of Theology, Education, Canon Law and Social Studies Inspired by Pope John Paul II”, „Studia Regionalne”. Do 2001 roku ukazywał się także periodyk „Religioni et Litteris”. Dlatego wydaje się słusznym w roku jubileuszowym diecezji tarnowskiej przypomnienie i zaprezentowanie wyżej wymienionych periodyków naukowych. Bowiem zarówno pracownicy naukowo-dydaktyczni WTST są kapłanami diecezji tarnowskiej, a sam wydział jako uczelnia można powiedzieć, iż jest instytucją diecezjalną.

\section{1. „TARNOWSKIE STUDIA TEOLOGICZNE”}

„Tarnowskie Studia Teologiczne” są naukowym, recenzowanym półrocznikiem, wydawanym od 1938 roku przez Wydział Teologiczny Sekcja w Tarnowie Uniwersytetu Papieskiego Jana Pawła II w Krakowie. Pierwsze cztery tomy były opublikowanymi rozprawami naukowymi: tom I: S. Adamczyk, Tomistyczna teoria poznawania zmysłowego, Tarnów 1938; tom II: S. Sroka, Nauka św. Cypriana o miłosierdziu chrześcijańskim, Tarnów 1939; tom III: J. Piskorz, Wiara parafian, Tarnów 1939; tom IV: S. Łach, Udział ubogich w dochodach beneficjalnych, Tarnów 1939. Wybuch II wojny światowej spowodował wstrzymanie wydawanie periodyku. Pismo zostało wznowione w 1972 roku i zawierało już wówczas teksty pracowników naukowych środowiska tarnowskiego jak i z poza tego środowiska. W latach 1972-1983 ukazało się pięć tomów. Natomiast od 1986 roku periodyk ukazywał się regularnie, najpierw jako rocznik, a od 1998 roku jako półrocznik. Obok artykułów znajdują się w nim przekłady tekstów i komentarze do nich, recenzje polskich i zagranicznych publikacji oraz sprawozdania ze sympozjów i kongresów.

Zostało wydanych kilka tzw. tomów okolicznościowych. Tom V (1972): Alma Mater Tarnoviensis stał się księgą pamiątkową z okazji 150. rocznicy założenia Instytutu Teologicznego i Seminarium Duchownego w Tarnowie (1821-1971), tom VII (1979) powstał z okazji 900. rocznicy męczeńskiej śmierci św. Stanisława, a tom VIII (1981) zawiera akta sympozjum patrystycznego poświęconego modlitwie starożytnych chrześcijan, które odbyło się w Tarnowie w październiku 1978 roku. Natomiast tom IX (1983): „Sanktuaria diecezji tarnowskiej” zawiera prezentację sanktuariów diecezji tarnowskiej: Pańskie, maryjne, świętych i sanktuaria zapomniane. Z kolei tom X część 1 (1986) był tomem jubileuszowym z okazji dwustu lat istnienia diecezji tarnowskiej 1786-1986 oraz tom X część 2 (1987) został dedykowany bp. Jerzemu Ablewiczowi, biskupowi tarnowskiemu, z okazji 
25-lecia posługiwania. Artykuły zamieszczone w tomie XIV (1995-1996) zostały poświęcone Ojcu Świętemu Janowi Pawłowi II z okazji jego 50-lecia kapłaństwa. Kilka tomów zostało także dedykowanych kapłanom diecezji tarnowskiej: tom XII (1993): „Księdzu Prałatowi dr. Eugeniuszowi Krężlowi na pięćdziesięciolecie kapłaństwa”, tom XXI/1-2 (2002): „Tom dedykowany ks. prof. dr. hab. Janowi Dudziakowi w 50-lecie kapłaństwa”, tom XXIII (2004): „Tom dedykowany ks. dr. hab. Michałowi Bednarzowi w 65-lecie urodzin" oraz tom XXIV (2007) dedykowano ks. prałatowi dr. Adamowi Nowakowi, byłemu redaktorowi „Tarnowskich Studiów Teologicznych" z okazji jego 80. urodzin.

Aktualnie zespół redakcyjny tworzą: ks. dr Piotr Łabuda (sekretarz redakcji), ks. dr hab. Andrzej Michalik (redaktor naczelny), ks. dr hab. Janusz Królikowski, prof. UPJPII, ks. dr Jacek Nowak, ks. dr hab. Antoni Żurek. Natomiast w skład rady naukowej wchodzą: ks. prof. dr hab. Tadeusz Brzegowy (UPJPII Kraków), ks. prof. dr hab. Alojzy Drożdż (UŚ Katowice), ks. prof. dr hab. Michał Heller (UPJPII Kraków), ks. prof. dr hab. Antoni Paciorek (KUL Lublin), ks. prof. dr hab. Stanisław Ludwik Piech (UPJPII Kraków), ks. prof. dr hab. Tomasz Rozkrut (UPJPII Kraków), ks. prof. dr hab. Józef Stala (UPJPII Kraków), ks. prof. dr hab. Stanisław Wszołek (UPJPII Kraków) i ks. prof. dr hab. Andrzej Zając (UPJPII Kraków).

Dotychczas ukazały się następujące numery „Tarnowskich Studiów Teologicznych":

1. „Tarnowskie Studia Teologiczne”, t. I: S. Adamczyk, Tomistyczna teoria poznania zmysłowego, Tarnów 1938.

2. „Tarnowskie Studia Teologiczne”, t. II: S. Sroka, Nauka św. Cypriana o miłosierdziu chrześcijańskim, Tarnów 1939.

3. „Tarnowskie Studia Teologiczne”, t. III: S. Łach, Udział ubogich w dochodach beneficjalnych, Tarnów 1939.

4. „Tarnowskie Studia Teologiczne”, t. IV: J. Piskorz, Wiara parafian - studium duszpasterskie, Tarnów 1939.

5. „Tarnowskie Studia Teologiczne” (1972), t. V.

6. „Tarnowskie Studia Teologiczne” (1977), t. VI.

7. "Tarnowskie Studia Teologiczne” (1979), t. VII.

8. „Tarnowskie Studia Teologiczne” (1981), t. VIII.

9. "Tarnowskie Studia Teologiczne" (1983), t. IX.

10. „Tarnowskie Studia Teologiczne” (1986), t. X, część 1.

11. „Tarnowskie Studia Teologiczne” (1987), t. X, część 2.

12. „Tarnowskie Studia Teologiczne” (1992), t. XI.

13. „Tarnowskie Studia Teologiczne” (1993), t. XII.

14. „Tarnowskie Studia Teologiczne” (1994), t. XIII.

15. „Tarnowskie Studia Teologiczne” (1995-1996), t. XIV.

16. „Tarnowskie Studia Teologiczne” (1997), t. XV.

17. „Tarnowskie Studia Teologiczne” (1998), t. XVI.

18. „Tarnowskie Studia Teologiczne” (1998), t. XVII. 
19. „Tarnowskie Studia Teologiczne” (1999), t. XVIII/1.

20. „Tarnowskie Studia Teologiczne” (1999), t. XVIII/2.

21. „Tarnowskie Studia Teologiczne” (2000), t. XIX/1.

22. "Tarnowskie Studia Teologiczne” (2000), t. XIX/2.

23. „Tarnowskie Studia Teologiczne” (2001), t. XX/1.

24. „Tarnowskie Studia Teologiczne” (2001), t. XX/2.

25. „Tarnowskie Studia Teologiczne” (2002), t. XXI/1-2.

26. „Tarnowskie Studia Teologiczne” (2003), t. XXII/1.

27. „Tarnowskie Studia Teologiczne” (2003), t. XXII/2.

28. "Tarnowskie Studia Teologiczne” (2004), t. XXIII.

29. „Tarnowskie Studia Teologiczne” (2005), t. XXIV/1.

30. „Tarnowskie Studia Teologiczne” (2005), t. XXIV/2.

31. „Tarnowskie Studia Teologiczne” (2006), t. XXV/1.

32. „Tarnowskie Studia Teologiczne” (2006), t. XXV/2.

33. „Tarnowskie Studia Teologiczne” (2007), t. XXVI.

34. „Tarnowskie Studia Teologiczne” (2007), t. XXVI/2.

35. „Tarnowskie Studia Teologiczne” (2008), t. XXVII/1.

36. „Tarnowskie Studia Teologiczne” (2008), t. XXVII/2.

37. „Tarnowskie Studia Teologiczne” (2009), t. XXVIII/1.

38. „Tarnowskie Studia Teologiczne” (2010), t. XXVIII/2.

39. „Tarnowskie Studia Teologiczne” (2010), t. XXIX/1.

40. „Tarnowskie Studia Teologiczne” (2010), t. XXIX/2.

41. „Tarnowskie Studia Teologiczne” (2011), t. XXX/1.

42. „Tarnowskie Studia Teologiczne” (2011), t. XXX/2.

2. MIĘDZYNARODOWY PERIODYK

"THE PERSON AND THE CHALLENGES:

THE JOURNAL OF THEOLOGY, EDUCATION, CANON LAW AND SOCIAL STUDIES INSPIRED BY POPE JOHN PAUL II"

Punktem odniesienia periodyku naukowego „The Person and the Challenges” są przede wszystkim myśli, refleksje i nauczanie papieża Jana Pawła II, który doceniając wartość osoby, często podkreślał jej godność, prawa i obowiązki. W czasie trwania swego pontyfikatu w latach 1978-2005 Jan Paweł II ubogacił nauczanie Kościoła olbrzymią ilością zróżnicowanych dokumentów: encyklik, adhortacji, bulli, konstytucji apostolskich, listów, orędzi, katechez i przemówień. Jednocześnie z perspektywy czasu można mówić o swoistym sposobie kontaktowania się Jana Pawła II ze swoimi słuchaczami, a szczególnie z ludźmi młodymi, którzy byli bardziej otwarci na jego słowo mówione niż zapisane. Dlatego wydaje się potrzebne, szczególnie u początku XXI wieku, wieku wielkiego postępu cywilizacji, myśli technicznej i rozwoju demokracji, a zarazem zagrożeń integralnego rozwoju człowieka, nawiązanie do wskazań zostawionych przez Jana Pawła II. 
Niniejszy periodyk doskonale wpisuje się w beatyfikację Ojca Świętego Jana Pawła II, która odbyła się 1 maja 2011 roku na Watykanie oraz działalność Wydziału Teologicznego Sekcja w Tarnowie i całego Uniwersytetu Papieskiego Jana Pawła II w Krakowie, którego celem ${ }^{1}$ jest zgłębianie depozytu wiary, rozwijanie badań z zakresu filozofii i innych dyscyplin naukowych ${ }^{2}$. Natomiast „Wydział Teologiczny Sekcja w Tarnowie jest kontynuatorem Instytutu Teologicznego w Tarnowie. Specyfika Wydziału wyraża się w jego kościelnej osobowości prawnej oraz w strukturze organizacyjnej, zwłaszcza w osobie i kompetencjach Wielkiego Wicekanclerza oraz w znaczeniu Wydziału dla życia i misji Kościoła tarnowskiego. Celem Wydziału jest wszechstronne i systematyczne badanie Bożego Objawienia, w różnych epokach i przejawach życia Kościoła oraz człowieka”’.

Tytul periodyku "The Person and the Challenges: The Journal of Theology, Education, Canon Law and Social Studies Inspired by Pope John Paul II" nawiązuje do tytułu książki Osoba i czyn ${ }^{4}$ kard. Karola Wojtyły, późniejszego papieża Jana Pawła II. Przypomina, iż tylko osoba „,zyni”, działa, postępuje, dokonuje aktów moralnych, tworzy historię. Osoba realizuje się w czynie, wyraża się w nim, przejawia, integruje. Osoba spełnia się przez czyn w swej istocie i w swym istnieniu. Według zamierzeń redaktorów "The Person and the Challenges" treści podejmowane w periodyku będą dotyczyć osoby oraz szeroko rozumianych wyzwań stojących przed osobą żyjącą w XXI wieku, jak również zagrożeń samej godności osoby, która poprzez różnorodne ograniczenia nie może być osobą. Konieczność podejmowania nowych wyzwań politycznych, społecznych, kulturowych oraz poszukiwania odpowiedzialnego świadectwa chrześcijańskiego w jakościowo nowych warunkach nie jest więc wyłącznym doświadczeniem obecnego pokolenia. Jednak niektóre wyzwania stają się obecnie coraz bardziej zagrożeniem. Dlatego wspólnym zadaniem dla wszystkich, którzy na początku trzeciego tysiąclecia chcą solidarnie odpowiadać na aktualne wyzwania, jest dociekanie wielkich wartości nadających sens poszukiwaniom osoby. Nadto ważne miejsce winna zajmować troska o rozwój osoby, o jej pełne, integralne wychowanie, o społeczeństwo miłości - cywilizację miłości. Uznanie myśli, refleksji i nauczania Jana Pawła II oraz potrzeba ponownego odkrycia jego wskazań w kontekście wyzwań XXI wieku

1 Por. Statut Uniwersytetu Papieskiego Jana Pawła II w Krakowie, Nr 5.

2 „Uniwersytet Papieski Jana Pawła II w Krakowie jest uniwersytetem kościelnym, kanonicznie erygowanym przez Stolicę Apostolską. Kontynuuje on, zgodnie ze współczesnymi potrzebami Kościoła w Polsce, historyczną misję Wydziału Teologicznego Uniwersytetu Jagiellońskiego i Papieskiej Akademii Teologicznej w Krakowie. Uniwersytet Papieski Jana Pawła II w Krakowie jest uczelnią kościelną, której charakter i działalność określa Konstytucja Apostolska Sapientia christiana. Uniwersytet zajmuje się badaniem i przekazywaniem wiedzy teologicznej i innych nauk humanistycznych, nadaje tytuły zawodowe, stopnie naukowe i tytuł naukowy powagą Stolicy Apostolskiej”. Statut Uniwersytetu Papieskiego Jana Pawła II w Krakowie, Nr 1-2.

3 Statut Uniwersytetu Papieskiego Jana Pawła II w Krakowie, Nr 143-144.

4 Zob. K. Wojtyła, Osoba i czyn, Kraków 2000. 
kierowały powstaniem tego pisma, jak również potrzeba wymiany naukowej, ciągłego rozwoju nauki, zgodnie z założeniami nauki Kościoła i wskazaniami the European Commission dotyczącymi edukacji w strategii „Europe 2020”.

Międzynarodowy periodyk "The Person and the Challenges" to recenzowane pismo naukowe powstałe w celu upowszechniania międzynarodowych badań w zakresie teologii, edukacji, prawa kanonicznego i studiów społecznych inspirowanych osobą i nauczaniem papieża Jana Pawła II podejmujące dyskusję dotyczącą zagadnień z zakresu powyższych i innych zbliżonych dziedzin. W "The Person and the Challenges" są zamieszczane znaczące naukowo, dotychczas nie publikowane, prace: artykuły jak również sprawozdania ze znaczących konferencji i recenzje książek. Publikowane są teksty (w języku angielskim, niemieckim, hiszpańskim, włoskim i francuskim) w wersji papierowej i w wersji elektronicznej (format PDF) na stronie internetowej pisma. Każdy artykuł napisany w jednym z ww. pięciu języków zawiera również w języku angielskim: tytuł, słowa klucze i abstrakt. Periodyk jest wydawany na Wydziale Teologicznym Sekcja w Tarnowie, Uniwersytetu Papieskiego Jana Pawła II w Krakowie, od 2011 roku, czyli roku beatyfikacji Ojca Świętego Jana Pawła II.

Redaktorem naczelnym jest ks. prof. dr hab. Józef Stala, zaś w skład zespołu redakcyjnego periodyku wchodzą: ks. dr Robert Kantor (Pontifical University of John Paul II in Cracow, Poland); ks. prof. UPJPII dr hab. Janusz Królikowski (Pontifical University of John Paul II in Cracow, Poland); p. prof. UKSW dr. hab. Elżbieta Osewska (Cardinal Stefan Wyszynski University in Warsaw, Poland); p. prof. KUL dr hab. Alicja Rynio (The John Paul II Catholic University of Lublin, Poland); ks. prof. UPJPII dr hab. Ireneusz Stolarczyk (Pontifical University of John Paul II in Cracow, Poland). Natomiast zaproszenie do Międzynarodowej Honorowej Rady Naukowej czasopisma przyjęli: ks. prof. dr hab. Tadeusz Brzegowy (Pontifical University of John Paul II in Cracow, Poland); br. prof. Dr. Herman Lombaerts (Catholic University of Leuven, Belgium); ks. prof. dr hab. Jan Łach (Cardinal Stefan Wyszynski University in Warsaw, Poland); prof. Dr. Hermann Rodriguez Osorio (Javeriana University of Bogota, Colombia); Prof. Dr. Flavio Pajer (Salesian Pontifical University - Rome, Italy); Prof. Dr. Graham Rossiter (Australian Catholic University, Australia); Prof. Dr. Peter Stilwell (Catholic University of Portugal, Portugal); Prof. Dr. Eloy Tejero (University of Navarrra, Spain); ks. prof. dr hab. Tadeusz Zasępa (The Catholic University in Ruzomberok, Slovakia). Z kolei do Międzynarodowej Rady Naukowej periodyku przyjęli zaproszenie: Prof. Dr. Alejandro W. Bunge (Pontifical Catholic University of Argentina, Argentina); ks. prof. dr hab. Tadeusz Dola (The University of Opole, Poland); ks. prof. dr hab. Alojzy Drożdż (University of Silesia in Katowice, Poland); Prof. Dr Roberto Jaramillo Escutia (Pontifical University of Mexico, Mexico); Prof. Dr. Franz Feiner (The Catholic University College for Teacher Training Graz, Austria);

5 Por. http://ec.europa.eu/education/lifelong-learning-policy/doc28_en.htm (8 VIII 2011). 
Dr. Adrian-Mario Gellel (University of Malta, Malta); Prof. Dr. Stanko Gerjolj (University of Ljubljana, Slovenia); ks. prof. UKSW dr hab. Waldemar Graczyk (Cardinal Stefan Wyszynski University in Warsaw, Poland); ks. prof. KUL dr hab. Andrzej Kiciński (The John Paul II Catholic University of Lublin, Poland); Dr. Patricia Kieran (Mary Immaculate College, Limerick, Ireland); ks. prof. UAM dr hab. Bogusław Kochaniewicz (Adam Mickiewicz University in Poznan, Poland); ks. prof. UPJPII dr hab. Janusz Królikowski (Pontifical University of John Paul II in Cracow, Poland); p. prof. UKSW dr hab. Jolanta M. Marszalska (Cardinal Stefan Wyszynski University in Warsaw, Poland); ks. prof. dr hab. Janusz Mastalski (Pontifical University of John Paul II in Cracow, Poland); ks. prof. dr hab. Kazimierz Misiaszek (Cardinal Stefan Wyszynski University in Warsaw, Poland); p. prof. UKSW dr hab. Elżbieta Osewska (Cardinal Stefan Wyszynski University in Warsaw, Poland); Prof. Dr. Erika Prijatelj (University of Ljubljana, Slovenia); Prof. Dr. Augusto Sarmiento (University of Navarra, Spain); ks. prof. dr hab. Józef Stala (Pontifical University of John Paul II in Cracow, Poland); ks. prof. UPJPII dr hab. Ireneusz Stolarczyk (Pontifical University of John Paul II in Cracow, Poland); ks. prof. UPJPII dr hab. Władysław Zuziak (Pontifical University of John Paul II in Cracow, Poland).

Dotychczas ukazały się następujące numery "The Person and the Challenges":

1. "The Person and the Challenges" 1 (2011) nr 1.

2. "The Person and the Challenges" 1 (2011) nr 2.

\section{3. „STUDIA REGIONALNE”}

„Studia Regionalne” to rocznik naukowy wychodzący od 2007 roku. „Studia Regionalne" mają charakter regionalny, rozpatrywany pod względem teoretycznym, to znaczy mają służyć refleksji metodologicznej nad regionem jako kategorią życia i myślenia. Następnie są regionalne w sensie historyczno-kulturowym, to znaczy preferowane są artykuły poświęcone regionowi mieleckiemu (historia, ludzie, kultura, ekonomia), a także regionom i sprawom, które w jakiś sposób mają związek - nawet dość szeroki - z regionem mieleckim.

Redaktorem naczelnym „Studiów Regionalnych” jest ks. dr hab. Janusz Królikowski, prof. UPJPII, natomiast zespół redakcyjny tworzą: p. dr Jacek Krzysztof Danel, p. dr Irena Duszkiewicz, p. dr Włodzimierz Gąsiewski, p. dr Anna Gąsior, p. Jacek Krzysztofik, ks. dr Piotr Łabuda, p. dr Andrzej Skowron, ks. prof. dr hab. Józef Stala, p. dr Jolanta Witek. „Studia Regionalne” ukazują się przy współpracy naukowej Polskiego Towarzystwa Teologicznego Oddział w Tarnowie. Współpraca obejmuje przede wszystkim konsultacje merytoryczne (recenzje) oraz stanowi forum, w którym mogą prezentować wyniki swoich badań w zakresie specyfiki „Studiów Regionalnych”.

Dotychczas ukazały się następujące numery „Studiów Regionalnych” (w tym jeden podwójny): 
1. „Studia Regionalne” 1 (2007).

2. „Studia Regionalne” 2 (2008).

3. „Studia Regionalne” 3-4 (2009-2010).

4. „Studia Regionalne” 5 (2011).

\section{4. „RELIGIONI ET LITTERIS”}

„Religioni et Litteris” - takie hasło znajduje się nad głównym wejściem do budynku Wyższego Seminarium Duchownego w Tarnowie, a obecnie także Wydziału Teologicznego Sekcja w Tarnowie Uniwersytetu Papieskiego Jana Pawła II w Krakowie. Z tego hasła można wyczytać niejako program funkcjonowania jako uczelni teologicznej zarówno wcześniej Wyższego Seminarium Duchownego, Instytutu Teologicznego jak i obecnie Wydziału Teologicznego Sekcja w Tarnowie, Uniwersytetu Papieskiego Jana Pawła II w Krakowie - kształtować kandydatów do kapłaństwa oraz świeckich studentów teologii w perspektywie służby wierze i kulturze. Tak też należy patrzeć na periodyk „Religioni et Litteris”, który rozpoczęto wydawać w Wyższym Seminarium Duchownym w Tarnowie od 1947 roku w celu prowadzenia dialogu między wiarą, religią a nauką, kulturą, co tłumaczy również obrany tytuł periodyku - w służbie religii i kultury. Przez pierwsze lata (do 1992 roku włącznie) „Religioni et Litteris”, zazwyczaj jako rocznik, było redagowane i wydawane przez zespół kleryków i przeznaczony do „użytku wewnętrznego”. Na jego łamach poruszano tematy filozoficzne i teologiczne, a także sprawy dotyczące codziennego życia seminarium. Powyższe zadania seminaryjne niejako ,przejęła” nowa gazetka seminaryjna „Nova”, którą rozpoczęto wydawać od listopada 1991 roku. Natomiast tytuł i tradycję naukową „Religioni et Litteris” przejęła nowa redakcja „Religioni et Litteris", w skład której wchodzili już pracownicy naukowi Instytutu Teologicznego w Tarnowie. Redaktorem naczelnym był ks. Zbigniew Adamek, a skład redakcji na przestrzeni lat się zmieniał i w 1996 roku wyglądał następująco: Ks. Zbigniew Adamek (redaktor naczelny), ks. Stanisław Budzik, ks. Alojzy Drożdż, ks. Michał Drożdż, ks. Michał Heller, ks. Adam Kokoszka, ks. Antoni Koterla. Natomiast w kolejnym numerze z 1998 roku skład zespołu redakcyjnego wyglądał następująco: ks. Zbigniew Adamek, ks. Stanisław Budzik, ks. Michał Heller, ks. Adam Kokoszka, ks. Janusz Królikowski (redaktor naczelny). Zatem w latach 1992-1998 periodyk „Religioni et Litteris” ukazywał się w nowej szacie graficznej, jako półrocznik noszący podtytuł: „Pismo teologiczno-kulturalne”, w którym publikowano artykuły, dyskusje i recenzje. Po przerwie, w 2001 roku ukazał się ostatni tom „Religioni et Litteris” (nastąpiła zmiana formatu i sygnatury) i wówczas nosił podtytuł „Z zagadnień teologii i kultury”. Redaktorem naczelnym był ks. dr Janusz Królikowski, a komitet redakcyjny tworzyli: ks. mgr lic. Zbigniew Adamek, ks. prof. PAT dr hab. Stanisław Budzik, ks. prof. dr hab. Michał Heller i ks. dr Adam Kokoszka. 
Dotychczas ukazały się następujące numery „Religioni et Litteris”:

I. Jako pismo redagowane przez zespół klerycki :

1. „Religioni et Litteris” (1947).

2. „Religioni et Litteris” (1948).

3. „Religioni et Litteris” (1955).

4. „Religioni et Litteris” (1956).

5. „Religioni et Litteris” (1957).

6. „Religioni et Litteris” (1958).

7. „Religioni et Litteris” (1959).

8. „Religioni et Litteris” (1960).

9. „Religioni et Litteris” (1961).

10. „Religioni et Litteris” (1962).

11. „Religioni et Litteris” (1963).

12. „Religioni et Litteris” (1964).

13. „Religioni et Litteris” (1965).

14. „Religioni et Litteris” (1965-1966).

15. „Religioni et Litteris” (1966).

16. „Religioni et Litteris” (1966-1967).

17. „Religioni et Litteris” (1967).

18. „Religioni et Litteris” (1968).

19. „Religioni et Litteris” (1969).

20. „Religioni et Litteris” (1970).

21. „Religioni et Litteris” (1971).

22. „Religioni et Litteris” (1972).

23. „Religioni et Litteris” (1973).

24. „Religioni et Litteris” (1974).

25. „Religioni et Litteris” (1975).

26. „Religioni et Litteris” (1976).

27. „Religioni et Litteris” (1977).

28. „Religioni et Litteris” (1978).

29. „Religioni et Litteris” (1979).

30. „Religioni et Litteris” (1980).

31. „Religioni et Litteris” (1981).

32. „Religioni et Litteris” (1982).

33. „Religioni et Litteris” (1982-1983).

34. „Religioni et Litteris” (1983).

35. „Religioni et Litteris” (1984).

36. „Religioni et Litteris” (1985).

37. „Religioni et Litteris” (1986).

38. „Religioni et Litteris” (1987) nr 1-2.

39. „Religioni et Litteris” (1987) nr 3-4.

40. „Religioni et Litteris” (1989) nr 1-3. 
41. „Religioni et Litteris” (1990).

42. „Religioni et Litteris” (1991).

43. „Religioni et Litteris” (1992) nr 1-2.

II. Jako pismo redagowane przez zespół pracowników naukowych Instytutu Teologicznego w Tarnowie:

44. „Religioni et Litteris” (1992) nr 1-2.

45. „Religioni et Litteris” (1993) nr 3-4.

46. „Religioni et Litteris” (1994) nr 5-6.

47. „Religioni et Litteris” (1995) nr 7-8.

48. ,Religioni et Litteris” (1996) nr 9.

59. „Religioni et Litteris” (1998) nr 10.

50. „Religioni et Litteris” (2001) nr 1. 
